\title{
Why do we argue about route of hysterectomy? A call for dialogue
}

\author{
Andrew J. Walter ${ }^{1}$ \\ Received: 5 December 2016 / Accepted: 5 December 2016/Published online: 26 December 2016 \\ (C) The International Urogynecological Association 2016
}

As part of the Presidential Address given at the 42nd Annual Scientific Meeting of the Society of Gyneocologic Surgeons, I made a call for a national dialogue to increase the rate of vaginal hysterectomy to at least $40 \%$. I admit this number is arbitrary and is based upon an internal review of hysterectomies performed at The Permanente Group North Valley. Data revealed that about one half of patients were vaginally parous, had no suspicion for adnexal pathology, and had a uterus $<12$ weeks in size - technically the most straightforward candidates for vaginal hysterectomy. Doing $80 \%$ of these patients via the vaginal route would translate to a vaginal hysterectomy rate of $40 \%$. In addition, cases series and randomized controlled trials (from USA and international authors) confirm that this higher rate is feasible [1-4].

Level 1 evidence shows that vaginal hysterectomy is associated with reduced costs and equal to or reduced morbidity rates when compared with all other routes of hysterectomy. This evidence has led the American Congress of Obstetricians and Gynecologists to recommend vaginal hysterectomy whenever technically feasible [5, 6]. Despite this data and support, vaginal hysterectomy has never constituted $>20 \%$ of the total hysterectomies in the USA, and current use patterns suggest that rates are in decline, parallel with increased use of the more expensive endoscopic (predominately robotic) approaches [7-9].

Even though abdominal hysterectomy rates are also finally in decline, why is it that neither in the past nor currently has there been general concern that vaginal hysterectomy rates have been so low compared with rates determined to be feasible, especially in this era of constrained resources?

Andrew J. Walter

Andrew.J.Walter@kp.org

1 The Permanente Medical Group-North Valley, MOB2/3C, 1600 Eureka Road, Roseville, CA 95661, USA
I have asked this question and have received a number of reasonable responses; I will highlight two:

Surgeons who predominately perform robotic hysterectomy justify widespread use of the modality given (near) universal applicability and prior stability of abdominal hysterectomy rates despite decades of laparoscopic use and training; with the reduction in abdominal hysterectomy rates justifying the cost of the robotic platform and despite the existence of more cost-effective, minimally invasive modalities [10].

Surgeons who predominately perform laparoscopic hysterectomy make similar claims. Vaginal surgery rates have remained historically low and stable, indicating that most gynecologists are not comfortable with the procedure and that laparoscopy is more universally applicable, along with being more cost effective than robotic hysterectomy. In addition, if there is to be a national push for nonrobotic minimally invasive hysterectomy, then it is easier to train low-volume gynecologic surgeons in the performance of laparoscopic hysterectomy rather than vaginal hysterectomy [11].

This being said, the simple facts of hysterectomy remain. All total hysterectomies require a colpotomy incision with the possible addition of accessory small or large incision(s) to facilitate the procedure [12]. Thus, both common sense and high-quality evidence support not making accessory abdominal incisions when technically feasible. The kicker, of course, is the term "technically feasible." This definition depends greatly upon the individual patient surgeon skill/experience. There is no evidence to suggest that $100 \%$ of hysterectomies can be performed via the vaginal route. Regardless, since high rates of vaginal hysterectomy are feasible in general gynecology populations, this 
suggests that surgeon factors (most likely technical expertise and comfort and possibly other incentives) are the cause of low vaginal hysterectomy rates. Of course, I am not arguing that surgeons unskilled in vaginal hysterectomy should perform the procedure. However, given the benefits of vaginal hysterectomy, I believe it is important to discuss and then address the factors leading to this lack of technical expertise and comfort. These factors may include issues related to residency training, low surgical volumes after residency, and/or misaligned incentives.

In the USA, the combination of work-hour restrictions, reduced hysterectomy volume, and expansion of hysterectomy routes has created an environment in which the mean hysterectomy volume during residency frequently does not equal the number of cases required to achieve surgical proficiency [13-18]. This has resulted in 75\% of graduating chief residents reporting that they are uncomfortable performing vaginal hysterectomy [19]. Moreover, most practicing OB/GYNs in the USA are low-volume surgeons performing a mean of 3.1 hysterectomies per year, with $80 \%$ performing fewer than one per month $[20,21]$. In addition to increased complication rates, low-volume surgeons demonstrate reduced use of minimally invasive hysterectomy, particularly vaginal hysterectomy. Finally, in the US market where there is high penetration of the robotic platform, use of the surgical robot to facilitate hysterectomy for benign disease is heavily marketed to patients and surgeons, potentially creating improper incentives for robotic hysterectomy [22].

So, why do we argue? We know that vaginal hysterectomy demonstrates comparable morbidity rates but reduced costs compared with other minimally invasive options, making it a better option for patients. Instead of arguing about the best route of hysterectomy, let us follow the evidence, which supports a paradigm in which every patient who is a candidate has her hysterectomy performed via the vaginal route. It is time to start the dialogue to increase vaginal hysterectomy rates (to at least $40 \%$ and potentially higher). We need to find solutions to improve residency training, reduce the number of low-volume surgeons, create proper incentives for performance of vaginal hysterectomy, and determine - and subsequently correct—what other factors are responsible for the historically low rates of vaginal hysterectomy. By doing so, we will be improving the care of our patients by performing appropriate, safe, and cost-effective surgical therapy.

I encourage the readers of the International Urogynecology Journal to work on these issues on local, national, and international levels.

\section{References}

1. Kovac SR, Barhan S, Lister M, Tucker L, Bishop M, Das A. Guidelines for the selection of the route of hysterectomy: application in a resident clinic population. Am J Obstet Gynecol. 2002;187:1521-7.
2. Benassi L, Rossi T, Kaihura CT, Ricci L, Bedocchi L, Galanti B, et al. Abdominal or vaginal hysterectomy for enlarged uteri: a randomized clinical trial. Am J Obstet Gynecol. 2002;187:1561-5.

3. Nielsen SL, Daugbjerg SB, Gimbel H, Settnes A. Use of vaginal hysterectomy in Denmark: rates, indications and patient characteristics. Acta Obstet Gynecol Scand. 2011;90:978-84.

4. Lönnerfors C, Reynisson P, Persson J. A randomized trial comparing vaginal and laparoscopic hysterectomy vs robot-assisted hysterectomy. J Minim Invasive Gynecol. 2015;22:78-86.

5. American College of Obstetrics and Gynecology. ACOG Committee Opinion No. 444: choosing the route of hysterectomy for benign disease. Obstet Gynecol. 2009;114:1156-8.

6. Nieboer TE, Johnson N, Lethaby A, Tavender E, Curr E, Garry R, et al. Surgical approach to hysterectomy for benign gynaecological disease. Cochrane Database Syst Rev 2009:1-132.

7. Wright JD, Herzog TJ, Tsui J, et al. Nationwide trends in the performance of inpatient hysterectomy in the United States. Obstet Gynecol. 2013;122:233-41.

8. Moen M, Walter AJ, Harmanli O, Cornella J, Nihira K, et al. Considerations for evidenced based use of vaginal hysterectomy in benign gynecology. Obstet Gynecol. 2014;124:585-9.

9. Jacoby VL, Autry A, Jacobson G, Domush R, Nakagawa S, et al. Nationwide use of laparoscopic hysterectomy compared with abdominal and vaginal approaches. Obstet Gynecol. 2009;114:1041-8.

10. Payne TN. In reply to robotically assisted hysterectomy in patients with large uteri: outcomes in five community practices. Obstet Gynecol. 2010;116:194.

11. Einarson J personal communication.

12. Moen M, Noone M, Cholkeri-Singh A, Vassallo B, Locker B, et al. Progressive reduction in abdominal hysterectomy rates - impact of laparoscopy, robotics and surgeon factors. J Robot Surg. 2014;8:13-7.

13. Jelovesek JE, Walters MD, Korn A, et al. Establishing cutoff scores on assessments of surgical skills to determine surgical competence. Am J Obstet Gynecol. 2010;203:81. e1-6.

14. Altgassen C, Michels W, Schneider A. Learning laparoscopic assisted hysterectomy. Obstet Gynecol. 2004;104:308-13.

15. Tunitsky E, Citil A, Ayaz R, Esin S, Knee A, Harmanli O. Does surgical volume influence short-term outcomes of laparoscopic hysterectomy? Am J Obstet Gynecol. 2010;203:24. e1-6.

16. Twijnstra AR, Blikkendaal MD, van Zwet EW, van Kesteren PJ, de Kroon CD, Jansen FW. Predictors of successful surgical outcome in laparoscopic hysterectomy. Obstet Gynecol. 2012;119:700-8.

17. Rashid TG, Kini M, Ind TE. Comparing the learning curve for robotically assisted and straight stick laparoscopic procedures in surgical novices. Int J Med Robot. 2010;6:306-10.

18. Woelk JL, Casiano ER, Weaver AL, Gostout BS, Trabuco EC, Gebhart JB. The learning curve of robotic hysterectomy. Obstet Gynecol. 2013;121:87-95.

19. Pulliam SJ, Berkowitz LR. Smaller pieces of the hysterectomy pie: current challenges in resident surgical education. Obstet Gynecol. 2009;113:395-8.

20. Boyd LR, Novetsky AP, Curtin JP. Effect of surgical volume on route of hysterectomy and short term morbidity. Obstet Gynecol. 2010;116:909-15.

21. Rogo-Gupta LJ, Lewin SN, Kim JH, et al. The effect of surgical volume and outcomes and resource use with vaginal hysterectomy. Obstet Gynecol. 2010;116:1341-7.

22. Schiavone MB, Kuo EC, Naumann RW, Burke WM, Lewin SN, Neugut AI, et al. The commercialization of robotic surgery: unsubstantiated marketing of gynecologic surgery by hospitals. Am J Obstet Gynecol. 2012;207:174. e1-7. 